\title{
Experimental Performance Measures of Recycled Insulation Concrete Blocks from Construction and Demolition Waste
}

\author{
Doudou Liu ${ }^{1, *}$, Liang Qiao ${ }^{2,3}$ and Guozhong $\mathrm{Li}^{4}$ \\ ${ }^{1}$ School of Management Science and Engineering, Shandong University of Finance and Economics, Jinan, 250014, China \\ ${ }^{2}$ National Engineering Laboratory for Reducing Emissions from Coal Combustion, Engineering Research Center of Environmental \\ Thermal Technology of Ministry of Education, Shandong Key Laboratory of Energy Carbon Reduction and Resource Utilization, \\ Research Center for Sustainable Development, School of Energy and Power Engineering, Shandong University, Jinan, 250061, \\ China \\ ${ }^{3}$ Housing and Urban-Rural Development Institute of Shandong Province, Jinan, 250004, China \\ ${ }^{4}$ School of Materials Science and Engineering, University of Jinan, Jinan, 250001, China \\ ${ }^{*}$ Corresponding Author: Doudou Liu. Email: liudoudou@sdufe.edu.cn
}

Received: 21 July 2021 Accepted: 10 September 2021

\begin{abstract}
Construction and demolition (C\&D) waste has seriously affected the ecological environment. The utilization of C\&D waste resources can greatly alleviate this problem, and it is an important way to help achieve the goal of zero carbon in 2050. In this study, insulation concrete blocks were developed with recycled aggregates, cement, fly ash as main raw materials, expanded polystyrene (EPS) insulation boards as block insulation filling material, and selfdeveloped construction waste composite activator, interface enhancer, surface modifier and other additives. Through experimental research and performance test analysis, the best mix ratio of the product and the mechanism of each additive were proved. The experimental results showed that the insulation concrete block prepared under the conditions of recycled aggregates sand ratio of $45 \%$, active activator $\mathrm{Na}_{2} \mathrm{SO}_{4}$ content of $0.15 \%$ and fly ash content of $30 \%$ has the best performance and meets the relevant standards.
\end{abstract}

\section{KEYWORDS}

C\&D waste; recycled insulation concrete blocks; experimental performance

\section{Introduction}

Urbanization and urban renewal have led to a surge in C\&D waste. It is estimated that the annual C\&D waste in China is about 3.5 billion tons [1], and increases at a rate of about $10 \%$ per year. In 2018, China's carbon emissions of the production stage of construction materials accounted for $28.3 \%$ of the national carbon emissions [2]. The development model of construction industry, which is mainly characterized by non-renewable resources and energy [3], must turn to a new model of green resources and energy, ecologically friendly and high-quality development [4]. The rapid development of urbanization and infrastructure requires a lot of building materials such as sand and stone. On the one hand, a large number of C\&D waste is piled up and landfilled, which takes up land resources. On the other hand, construction materials are becoming increasingly scarce. C\&D waste consists mainly of concrete, bricks, 
metals, wood, plastics, gravel, ceramics and glass [5], most of which are reusable materials [6]. The EU produces about 850 million tons of C\&D waste annually, accounting for $31 \%$ of total waste generated within the EU [7]. The recycling rate of $\mathrm{C} \& \mathrm{D}$ reaches as high as $75 \%$ in some European countries [8], but the reuse rate is far less than that in China [9]. A large amount of C\&D waste in China provides sufficient raw materials for its large-scale treatment and resource utilization [10]. Therefore, the resource utilization of C\&D waste cannot only solve the environmental problems, but also alleviate the cost problem caused by the shortage of construction materials [11].

At present, the resource utilization mode of C\&D waste in China is mainly onsite utilization, and the waste into the plant for resource treatment projects is mainly waste concrete, broken bricks and tiles [12]. Recycled aggregates are mainly used in road base, roadbed, production of recycled aggregates bricks and blocks, recycled aggregates concrete and mortar $[13,14]$. Aggregates account for $70 \%-80 \%$ of the total volume of concrete [15]. The annual consumption of aggregates in China is about 20 billion tons, accounting for nearly $50 \%$ of the world's annual output $[16,17]$. As a substitute for storing C\&D waste in landfills, the use of recycled aggregates creates a new market opportunity for development [18]. C\&D waste recycled aggregates partially or completely replace traditional aggregates to prepare concrete, which can not only reduce the damage to natural resources, but also reduce the cost of construction products [19]. At present, some research on the resource utilization of C\&D waste focus on the mechanical properties of recycled aggregates. The different sources of waste, production processes and uses of recycled products make the test results different. A study undertaken at the University of Liverpool has determined that levels of replacement of newly quarried with recycled demolition aggregates will not have a significant adverse impact on the mechanical properties of the concrete building blocks and concrete paving blocks [20,21]. Bravo et al. [22] analyzed the mechanical performance of concrete with recycled aggregates from C\&D waste from various locations in Portugal and concluded that the use of recycled aggregates worsens most of the properties tested, especially when fine RA is used. Zhang et al. [23] analyzed the physical and chemical properties of C\&D waste materials in subgrade engineering and the results showed that recycled $C \& D$ waste aggregates with proper grading and strict construction technologies perform well. Zhang conducted a comparative study on the mechanical and durability properties of fiber-reinforced concrete made from recycled coarse aggregates and natural aggregates [24].

With the comprehensive and mandatory implementation of China building energy-saving standards, the study and production of thermal insulation blocks have gradually become a research hotspot. Thermal insulation blocks of various materials, such as sintered coal gangue composite thermal insulation blocks [25], new volcanic slag self-insulation blocks [26,27] and HB concrete self-insulation blocks [28], have attracted the attention of scholars from different industry backgrounds. It is also one of the main research directions for scholars to use recycled aggregates from C\&D waste to produce blocks. The experimental research of thermal insulation block mainly focuses on its heat transfer coefficient and thermal insulation performance. Li et al. [29] used ceramsite and C\&D waste as coarse aggregates to prepare ceramsite concrete hollow block, and filled the holes of the hollow block with gypsum and polystyrene particles. The ratio, compressive strength and thermal performance were studied experimentally. Xu et al. [30] designed a new type of full-bridge insulation block. Compared with the traditional full-bridge insulation block, the compressive strength decreased by $2.5 \%$, but the insulation performance increased by $23.0 \%$. Zhang [31] tested the thermal performance of different block walls, and thought that the heat transfer coefficient of recycled concrete self-insulation block walls were affected by the amount of recycled fine aggregates and vitrified beads. Taking C\&D waste as coarse aggregates, He developed a new type of bearing and thermal insulation block with a thickness of $310 \mathrm{~mm}$. The test results showed that the heat transfer coefficient of recycled aggregates wall is lower than that of natural aggregates wall under the same conditions. The focus of experimental analysis of ordinary block is its compressive strength [32]. 
Liu et al. [33] conducted axial compression tests on 36 recycled concrete block masonry to study its compression failure characteristics and compression performance. The experimental analysis showed that the compressive strength design value is slightly lower than the compressive strength design value of concrete perforated brick masonry in the specification. Zhao manufactured concrete blocks with different replacement ratios of natural aggregates in the factory, and monitored their mechanical properties and durability [34]. Abdulmatin used calcium carbide residue and bagasse ash as substitute cementing materials for Portland cement, and used $100 \%$ recycled concrete aggregates instead of natural aggregates to make inter-locking concrete blocks and studied their performance [35]. Huang et al. [36] studied the influence of EPS filling method and filling rate on the thermal insulation performance of composite selfinsulation block, and considered that under the same filling rate, the filling of EPS should be as close as possible to the interior of the wall, which is more conducive to the insulation effect.

Based on the existing research results, the material composition of $C \& D$ waste was analyzed in detail. The composite activator, interface enhancer and composite surface modifier agent for C\&D waste were developed, which solved the problems of low reactivity of construction waste, poor interface bonding of construction waste building materials and high water absorption. Through experimental research and performance test analysis, the optimal mix proportion of insulation concrete block with construction waste as the main raw material was determined, and the action mechanism of each additive was proved. The products are tested by the relevant departments, and the performance indicators meet or exceed the requirements of JG/T 407-2013 "Self-thermal insulation concrete composite block".

\section{Test Materials}

\section{$2.1 C \& D$ Waste}

The C\&D waste used in this project is generated from the demolition of old buildings in urban areas.

The reinforcement and wood were sorted out firstly, and the main components of C\&D waste were waste concrete, waste brick and marble. The project cooperation company carried out coarse breading, sorting, magnetic separation, fine breaking and screening. The processed aggregates met the requirements of (GB/T 25176-2010) "Recycled fine aggregates for concrete and mortar".

\subsection{Cement}

The commercially available ordinary portland cement with the strength grade of 42.5 (P. O 42.5R) cement was used in this experiment, which met the requirements of the national standard GB 1751999 for ordinary portland cement.

\subsection{Fly Ash}

The fly ash is a byproduct formed in the process of pulverized coal combustion in coal-fired power plants. The fly ash used in this experiment is from a power plant, which belongs to grade II fly ash. The fly ash is tested according to GB/T 1596-2005 "Fly ash used in cement and concrete". Each index meets the standard requirements. The chemical composition analysis is shown in Table 1.

Table 1: Chemical composition of fly ash/\%

\begin{tabular}{llllllllll}
\hline Chemical composition & $\mathrm{SiO}_{2}$ & $\mathrm{Al}_{2} \mathrm{O}_{3}$ & $\mathrm{Fe}_{2} \mathrm{O}_{3}$ & $\mathrm{CaO}$ & $\mathrm{MgO}$ & $\mathrm{SO}_{3}$ & $\mathrm{Na}_{2} \mathrm{O}$ & $\mathrm{K}_{2} \mathrm{O}$ & Loss \\
\hline Content & 52.43 & 18.81 & 9.30 & 7.45 & 5.77 & 2.25 & 0.86 & 2.07 & 0.95 \\
\hline
\end{tabular}




\subsection{Slag Powder}

The fineness of the slag powder (SP) used in the experiment is 2000 meshes. The chemical composition and main physical properties are shown in Table 2.

Table 2: The chemical composition and main physical properties of SP

\begin{tabular}{lllllllll}
\hline Category & \multicolumn{4}{c}{ Chemical composition/\% } & $\begin{array}{l}\text { specific surface } \\
\text { area }\left(\mathrm{m}^{2} \cdot \mathrm{kg}^{-1}\right)\end{array}$ & $\begin{array}{l}\text { density } \\
\left(\mathrm{g} \cdot \mathrm{cm}^{-3}\right)\end{array}$ & $\begin{array}{l}\text { activity } \\
\text { index }(28 \mathrm{~d}) \%\end{array}$ \\
\cline { 2 - 6 } & $\mathrm{CaO}$ & $\mathrm{SiO}_{2}$ & $\mathrm{Al}_{2} \mathrm{O}_{3}$ & $\mathrm{Fe}_{2} \mathrm{O}_{3}$ & $\mathrm{MgO}$ & & 2.90 & 96 \\
\hline Content & 37.85 & 32.47 & 15.73 & 0.62 & 10.10 & 495 & 25 & 20 \\
\hline
\end{tabular}

\subsection{Water Glass}

Water glass was purchased in a chemical market.

\subsection{Polyvinyl Alcohol (PVA)}

PVA is a white powdered solid, which belongs to watersoluble polymer and is widely used.

\subsection{Composite Activator for Recycled Waste}

The surface reactivity of recycled aggregates prepared by C\&D waste is relatively low. In order to stimulate its potential activity, a composite activator for recycled aggregates of C\&D waste was developed and used in this experiment, which is mainly composed of sulfate and alkali substances compounded according to the appropriate ratio.

\subsection{Interface Enhancer}

Recycled aggregates and cement matrix interface bonding strength is relatively low, there will be many voids. In order to make the combination of the two more solid, a self-made interface enhancer used in this experiment was mainly prepared by PVA solution and redispersible emulsion powder in a certain proportion.

\subsection{Surface Modifier}

There are a large number of pores and cracks in recycled aggregates of $C \& D$ waste, which will lead to the low overall strength and density of recycled aggregates. In order to modify its surface, the research group developed a surface modifier, which was made of a certain proportion of SP slurry, water glass (WG) solution and polyvinyl alcohol (PVA) solution.

\subsection{Thermal Insulation Material}

The polystyrene foam insulation material-EPS insulation boards were used as the insulation filling material in the experiment. The main physical performance indexes are shown in Table 3.

Table 3: Main physical performance indexes of EPS insulation board

\begin{tabular}{lll}
\hline Physical performance & Unit & Index \\
\hline Apparent density & $\mathrm{kg} / \mathrm{m}^{3}$ & $18 \sim 20$ \\
Compression strength & $\mathrm{kPa}$ & $\geq 100$ \\
Thermal conductivity & $\mathrm{W} /(\mathrm{m} \cdot \mathrm{K})$ & $\leq 0.040$ \\
Tensile strength perpendicular to the plane & $\mathrm{MPa}$ & $\geq 0.10$ \\
Water absorption ( volume fraction ) & $\%$ & $\leq 3$ \\
Size stability & $\%$ & $\leq 0.3$ \\
Water vapor permeability coefficient & $\mathrm{ng} /(\mathrm{pa} \cdot \mathrm{m} \cdot \mathrm{s})$ & $\leq 4.5$ \\
Bending deformation & $\mathrm{mm}$ & $\geq 20$ \\
Combustion performance grade & & not lower than level B1 \\
\hline
\end{tabular}




\subsection{Other Materials}

Water reducer, fly ash active activator and other additives are also used in this experiment. The water used in the test is ordinary tap water.

\section{Test Process and Method}

\subsection{Preparation Technology of Recycled Aggregates from Construction Waste}

The preparation process of C\&D waste recycled aggregates is shown in Fig. 1. First, the bulk of C\&D waste generated by demolition was hammered, vibrated and crushed, and then transported back to the project cooperation company for primary crushing by jaw crusher. The crushed $C \& D$ waste was subjected to impurity separation and magnetic separation to remove wood, organic materials and iron materials. Then, 0-40 $\mathrm{mm}$ aggregates was obtained after the first stage screening. The fine aggregates with the particle size of $0.15-5 \mathrm{~mm}$ and coarse aggregates with the particle size of 5-20 mm were finally obtained by secondary crushing and screening. Fine powder less than $0.15 \mathrm{~mm}$ produced during processing can be used as backfill or mortar mixture after screening lime soil. The recycled aggregates meet the secondary particle gradation of the standard requirements of GB/T 25176-2010 "Recycled fine aggregates for concrete and mortar". The recycled aggregates of C\&D waste crushing are shown in Fig. 2.

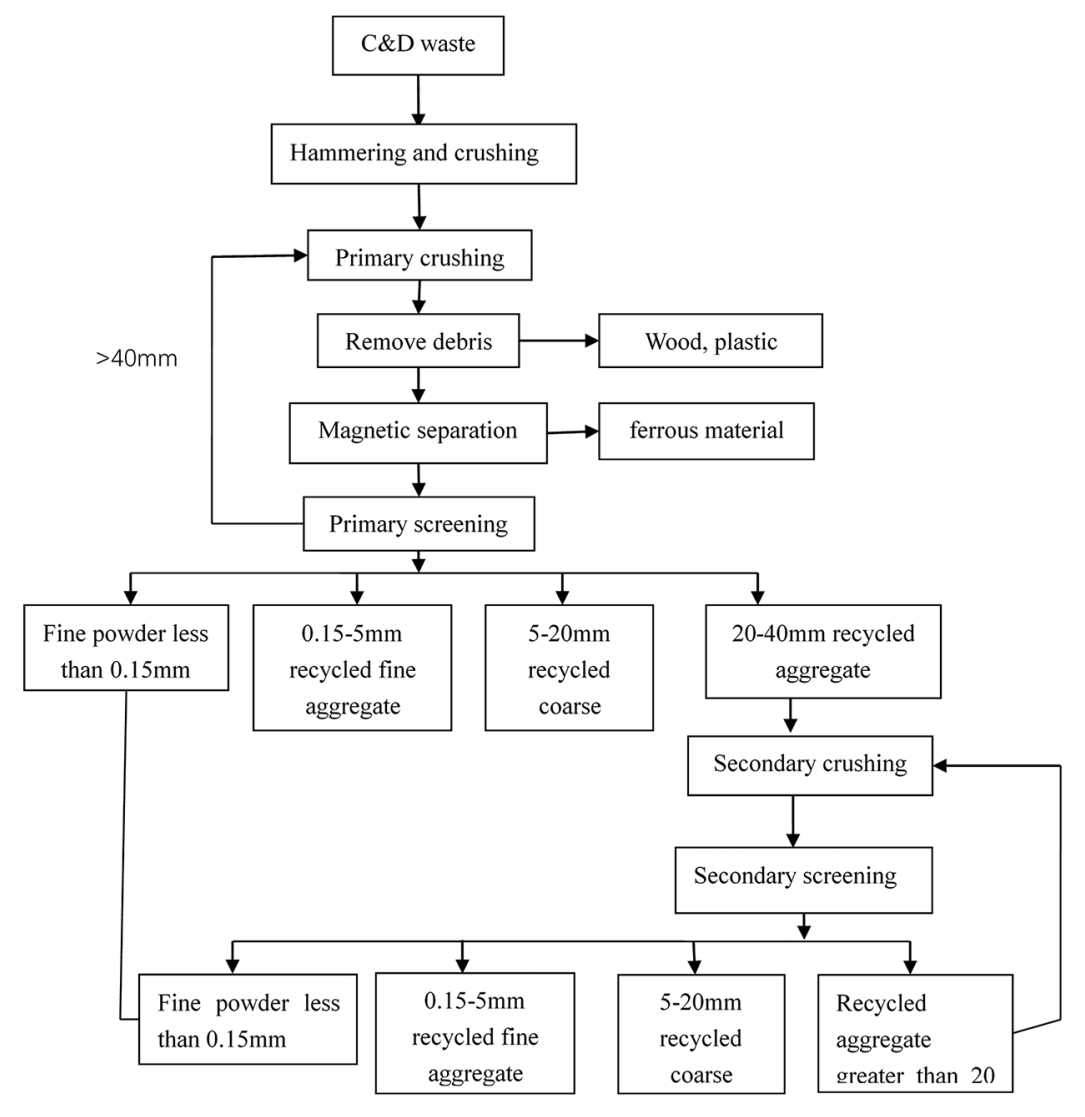

Figure 1: Flow chart of $C \& D$ waste recycled aggregates preparation 

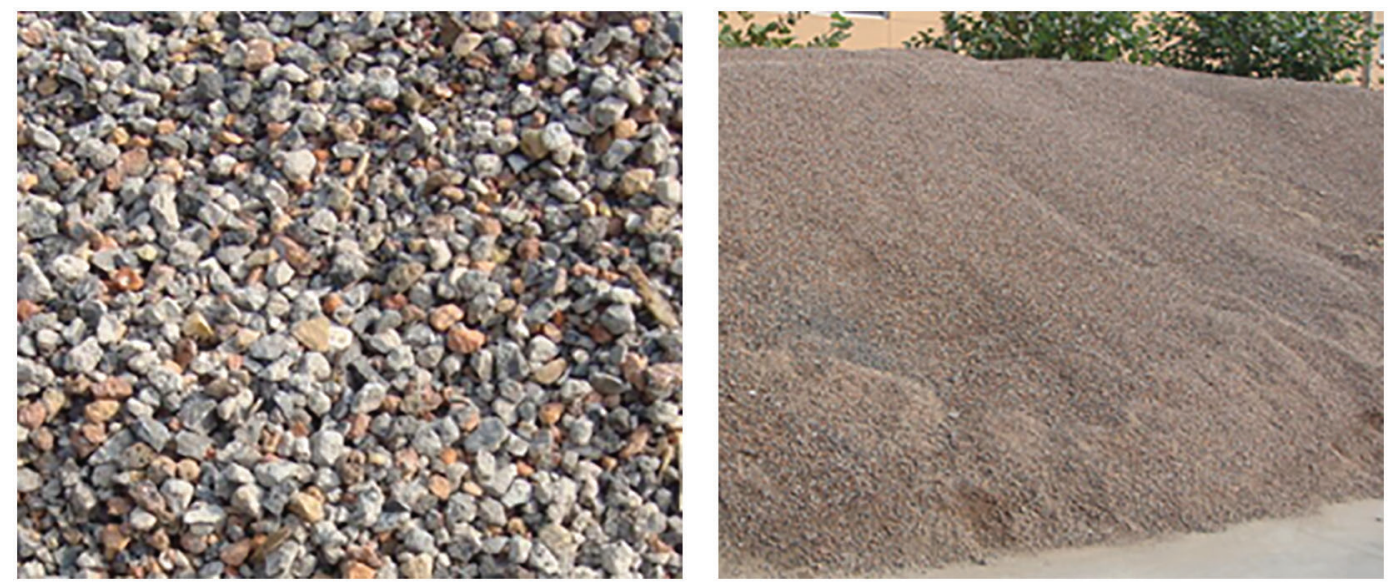

Figure 2: Recycled aggregates from $C \& D$ waste

\subsection{Modification of Recycled Aggregates from C\&D Waste}

There are a large number of holes and cracks on the surface of recycled aggregates of C\&D waste. The existence of these holes and cracks will reduce the overall strength and density of recycled aggregates, and the water absorption and crushing index are significantly increased. That is, the quality of recycled aggregates is poor. Therefore, surface modification of $\mathrm{C} \& \mathrm{D}$ waste recycled aggregates is very important and necessary.

The modification method of this experiment is as follows: Firstly, SP slurry, WG solution and PVA solution with certain mass concentration are prepared, respectively. The recycled aggregates are soaked in the SP slurry for $1 \mathrm{~h}$, and then are taken out for air-drying. Then the recycled aggregates after air-dried are soaked in the PVA solution for $1 \mathrm{~h}$, and closed then is taken out for air-drying. According to the above method, the modified recycled aggregates samples 2-8 were obtained after soaking in different solutions and air-drying. The solution concentration and test ratio are shown in Table 4.

Table 4: Solution concentration and test ratio of composite modified recycled aggregates

\begin{tabular}{llll}
\hline No. & SP slurry $\%$ & WG solution $\%$ & PVA solution $\%$ \\
\hline 0 & - & - & - \\
1 & 5 & - & 5 \\
2 & - & 5 & 10 \\
3 & - & 10 & 5 \\
4 & 10 & - & 10 \\
5 & 10 & 5 & 5 \\
6 & 10 & 5 & 10 \\
7 & 10 & 10 & 5 \\
8 & 10 & 10 & 10 \\
\hline
\end{tabular}

\subsection{Preparation Technology of Thermal Insulation Concrete Block}

Using cement, fly ash, recycled aggregates of C\&D waste and EPS insulation board as main raw materials, the insulation concrete block was prepared by adding composite activator, composite waterproofing agent and interface strengthening agent of insulation materials. The surface of EPS 
insulation board needs to be sprayed with interfacial strengthening agent to ensure the strong bonding between EPS insulation board and matrix material. The interface treated EPS insulation board was preset to the fixed position in the grinder. Other materials are compounded with EPS insulation board by metering and mixing, and then demoulded and cured to produce insulation concrete block. The insulation block is shown in Fig. 3. The production process is shown in Fig. 4.

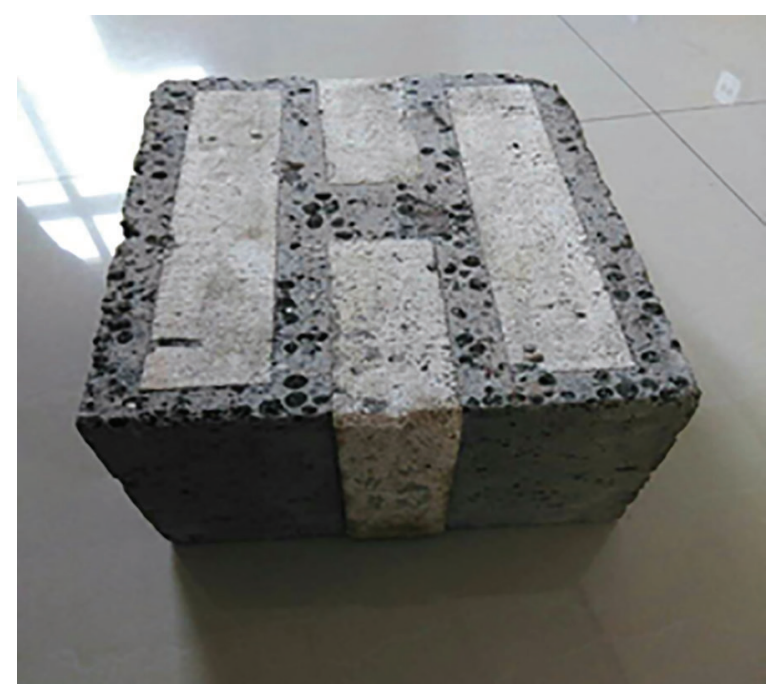

Figure 3: Sample photos

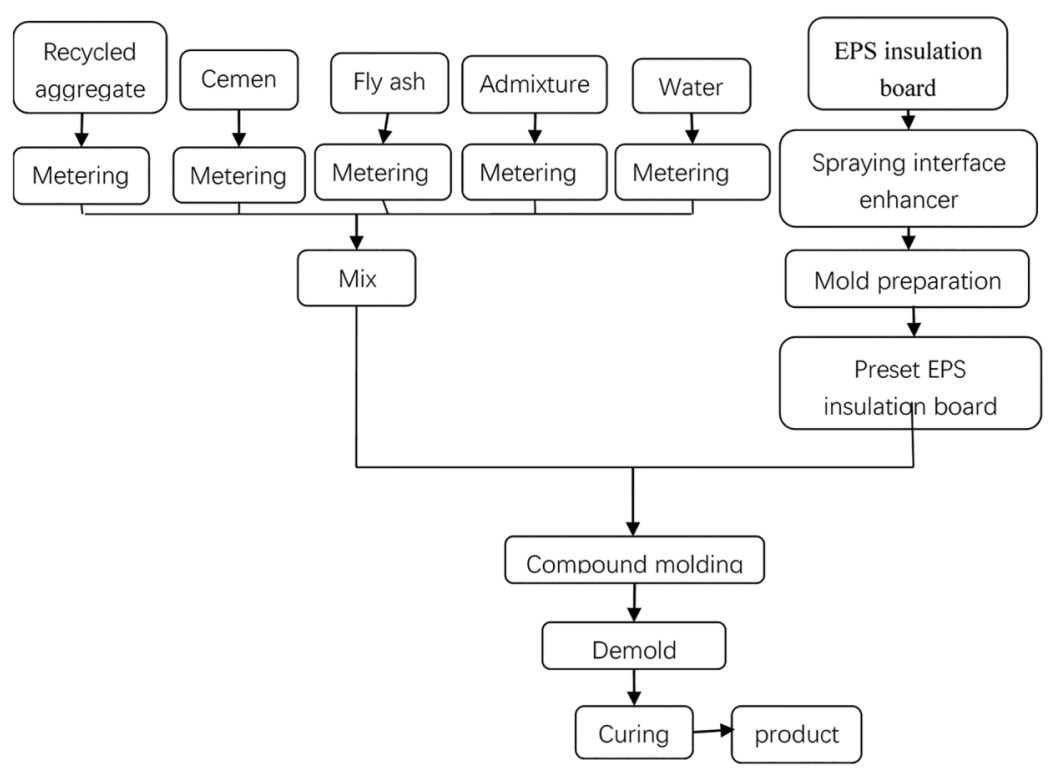

Figure 4: Production process diagram of thermal insulation concrete blocks

\section{Results and Discussion}

\subsection{Surface Modification Analysis of Recycled Aggregates}

\subsubsection{Effect of Composite Modification on Saturated Water Absorption of Recycled Aggregates}

Test the saturated water absorption performance of modified recycled aggregates in Table 4, and the results are shown in Table 5 and Fig. 4. 
Table 5: Saturated water absorption of composite modified recycled aggregates

\begin{tabular}{llllllllll}
\hline No. & 0 & 1 & 2 & 3 & 4 & 5 & 6 & 7 & 8 \\
\hline Saturated water absorption \% & 12.7 & 8 & 7 & 6.3 & 5 & 4.4 & 2.7 & 3.1 & 2.9 \\
\hline
\end{tabular}

Fig. 5 shows the effects of different modification methods on the saturated water absorption of recycled aggregates. Compared the Sample 1 and Sample 4, we found the influence of slurry concentration on the saturated water absorption of recycled aggregates was obvious, and the saturated water absorption decreased from $8 \%$ to $5 \%$. Compared with the unmodified sample 0 , the saturated water absorption of Samples 5-8 modified by three solutions decreased significantly. In addition, by comparing 5-8 samples, it can be found that the concentration change of WG solution and PVA solution had little effect on the saturated water absorption rate. The saturated water absorption of recycled aggregates after composite modification changed obviously, which was significantly lower than that of Sample 0, and the effect was good. Sample 6 modified by 10\% SP slurry, 5\% WG solution and 10\% PVA solution had the best effect, and its saturated water absorption is only $2.7 \%$, which is $10 \%$ lower than that of Sample 0 without modification.

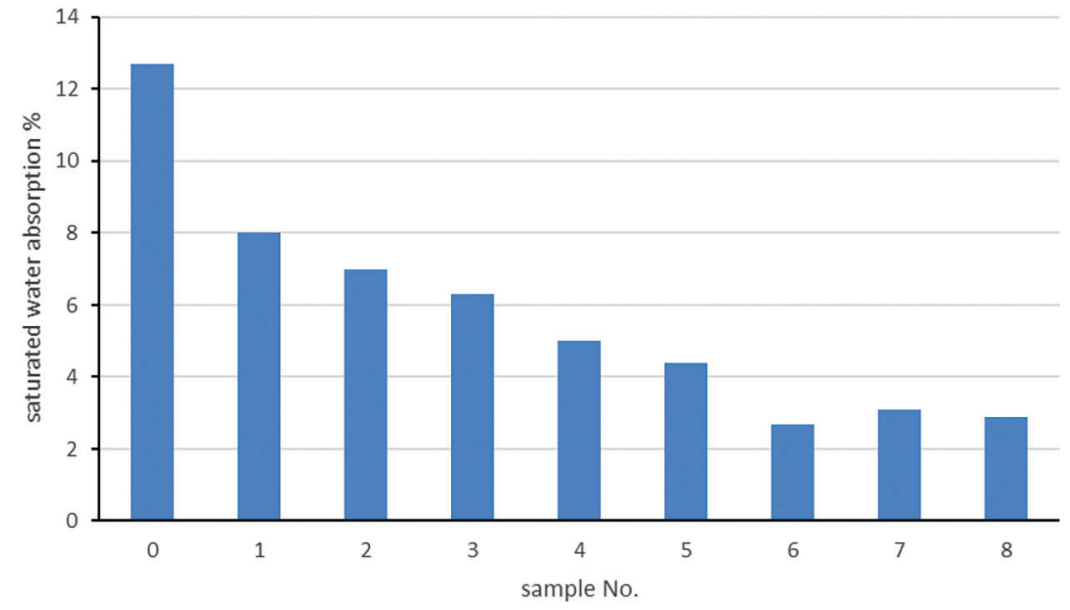

Figure 5: Saturated water absorption of composite modified recycled aggregates

Table 6: Crushing index of composite modified recycled aggregates

\begin{tabular}{llllllllll}
\hline No. & 0 & 1 & 2 & 3 & 4 & 5 & 6 & 7 & 8 \\
\hline Crushing index \% & 23 & 14.2 & 13.8 & 12.7 & 12.1 & 11.5 & 10.4 & 8.7 & 10.6 \\
\hline
\end{tabular}

\subsubsection{Effect of Composite Modification on Crushing Index of Recycled Aggregates}

The crushing index of construction waste recycled aggregates was tested according to the concrete recycled aggregates standard GB/T 25177-2010. The test results are shown in Table 6 and Fig. 5.

It can be clearly seen from Fig. 6: Compared with Sample 1 and Sample 4, the solution concentration had a certain influence on the crushing index of recycled aggregates, and the crushing index decreased with the increase of treatment solution concentration. Compared with the crushing index of Samples 5-8, the change was not obvious, but the crushing index was low, indicating that the WG solution can promote the modification of SP slurry on aggregates to a certain extent. 


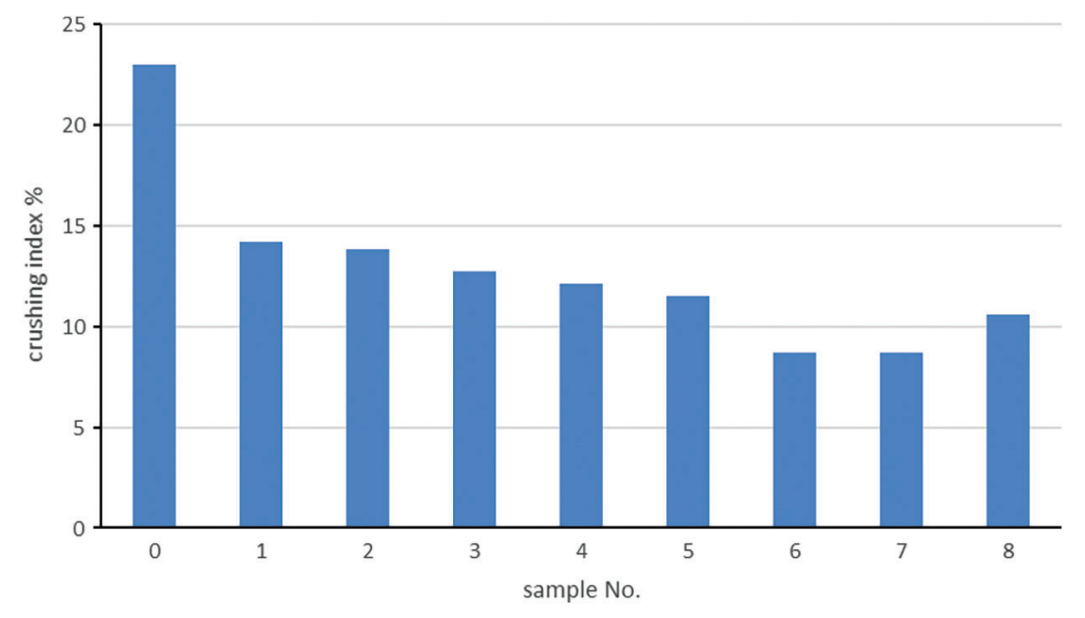

Figure 6: Crushing index of composite modified recycled aggregates

The crushing index value of recycled aggregates samples after composite modification changed significantly, and decreased greatly. The crushing index value of Sample 7 is only $8.7 \%$, which is $14.3 \%$ lower than that of Sample 0 without modification.

\subsubsection{Surface Micro-Morphology Analysis and Modification Mechanism of Composite Modified Recycled} Aggregates

The scanning electron microscope (SEM) of Sample 0 without modification of C\&D waste recycled aggregates is shown in Fig. 7a. The SEM of Sample 4 modified by SP slurry and PVA solution is shown in Fig. 7b. The SEM of Sample 6 modified by SP slurry, WG solution and PVA solution is shown in Fig. 7c.

After modification, the recycled aggregates of $C \& D$ waste will produce more cementitious products attached to the surface of the aggregates, and defects such as pores and cracks of the recycled aggregates will be filled by a large number of hydration products. The main reason is that the particle size of SP is small, which is significantly smaller than that of fly ash and cement particles. It is easier to fill the tiny holes and gaps on the aggregates surface, so that the hydration products can effectively fill the defects such as micro cracks and pores, and make the aggregates structure more compact. WG and PVA solutions are used to further modify the aggregates. WG and PVA solution can promote the hydration of SP and mix together to form a composite cementitious material, which is filled in the defects such as holes and cracks on the surface of recycled aggregates, so that the overall structural strength of recycled aggregates is improved.

When the C\&D waste composite modified recycled aggregates are used to prepare concrete, the modified interface can further improve the bonding strength between recycled aggregates and cement matrix. At the same time, the existence of PVA can also form a flexible interface layer between the two. The internal stress of concrete products is caused by the different shrinkage degrees of recycled aggregates and cement paste, and the existence of this flexible interface layer will reduce the internal stress.

Therefore, the recycled aggregates modified by SP, WG and PVA solution not only repair the defects on the surface of recycled aggregates, but also form an interface layer on the surface of recycled aggregates that is conducive to the combination with cement matrix materials, which is conducive to improving the strength and performance of concrete products. 


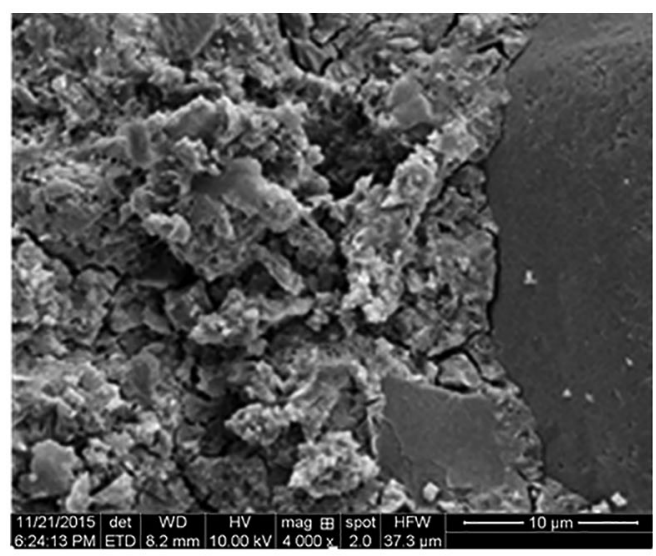

(a)

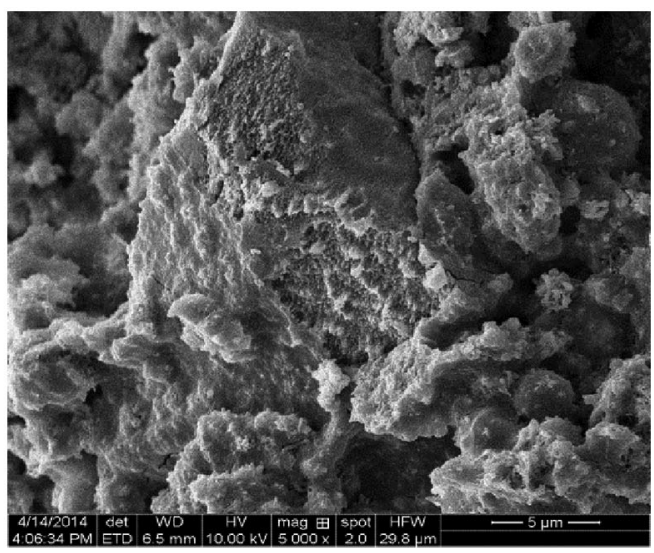

(b)

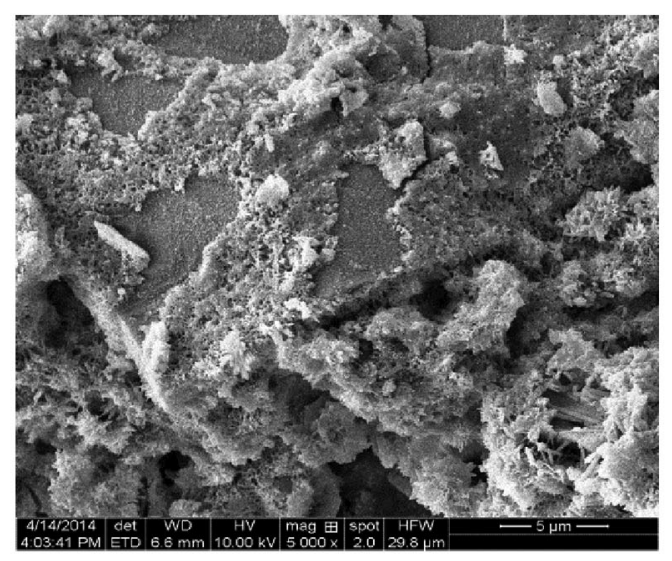

(c)

Figure 7: SEM of recycled aggregates sample (a) Sample 0 without modification (b) Sample 4 modified by SP slurry and PVA solution (c) Sample 6 modified by SP slurry, WG solution and PVA solution

\subsection{Experimental Performance Analysis of Recycled Thermal Insulation Block}

As a new type of non-load-bearing wall insulation material, it is very important to study the basic mechanical properties and thermal insulation performance of thermal insulation concrete blocks. The basic mechanical properties and thermal performance of insulation concrete blocks were experimentally studied, mainly including the influence of recycled aggregates sand ratio, recycled aggregates active activator, and fly ash content on the mechanical properties of blocks, and the influence of EPS insulation board's density on the thermal insulation performance.

The strength grade of the insulation concrete block is MU5.0, and the main specification size is $390 \mathrm{~mm} \times 240 \mathrm{~mm} \times 190 \mathrm{~mm}$.

\subsubsection{Effect of Recycled Aggregates Sand Ratio $\gamma$ on the Performance of Insulation Concrete Blocks}

In this experimental study, the ratio of cement to recycled aggregates is $1: 5$, the water-cement ratio is $36 \%$, and the dosage of water reducer is $1 \%$ of the cement content. The effect of recycled aggregates sand ratio $\gamma$, which is the ratio of recycled fine aggregates to recycled aggregates, on the strength of the block was investigated. The $28 \mathrm{~d}$ compressive strength of the test sample was analyzed and compared by changing the sand ratio of recycled aggregates and the best value of $\gamma$ was obtained. The test ratio and results are shown in Table 7 and Fig. 7. 
Table 7: Influence of recycled aggregates sand ratio on 28D compressive strength

\begin{tabular}{|c|c|c|c|c|c|c|c|}
\hline \multirow[t]{3}{*}{ No. } & \multicolumn{6}{|c|}{ Consumption per unit volume $/ \mathrm{kg} \cdot \mathrm{m}^{-3}$} & \multirow{3}{*}{$\begin{array}{l}28 \mathrm{~d} \text { compressive } \\
\text { strength }(\mathrm{MPa})\end{array}$} \\
\hline & \multirow[t]{2}{*}{ Cement } & \multicolumn{3}{|c|}{ Recycled aggregates } & \multirow[t]{2}{*}{ Water } & \multirow[t]{2}{*}{ Water reducing agent } & \\
\hline & & $\gamma$ & Fine aggregates & Coarse aggregates & & & \\
\hline 1 & 260 & 30 & 390 & 910 & 90 & 2.6 & 9.26 \\
\hline 2 & 260 & 35 & 455 & 845 & 90 & 2.6 & 9.66 \\
\hline 3 & 260 & 40 & 520 & 780 & 90 & 2.6 & 10.36 \\
\hline 4 & 260 & 45 & 585 & 715 & 90 & 2.6 & 10.56 \\
\hline 5 & 260 & 50 & 650 & 650 & 90 & 2.6 & 10.38 \\
\hline
\end{tabular}

Note: 28 days compressive strength takes the average strength of three specimens. When the difference between one of the maximum or minimum values of the three specimens and the intermediate value exceeds $15 \%$ of the intermediate value, the intermediate value is taken. When the difference between the maximum and minimum values of the strength of the three specimens and the intermediate value exceeds $15 \%$ of the intermediate value, this group should not be used as the basis for strength evaluation.

It can be seen from Table 7 and Fig. 8 that with the increase of recycled aggregates sand ratio $\gamma$, the 28day compressive strength of the insulation concrete block shows a trend of first increase and then decrease, and when the value of $\gamma$ is $45 \%$, the maximum strength is $10.56 \mathrm{MPa}$. The experimental results are basically consistent with the research results of some scholars.

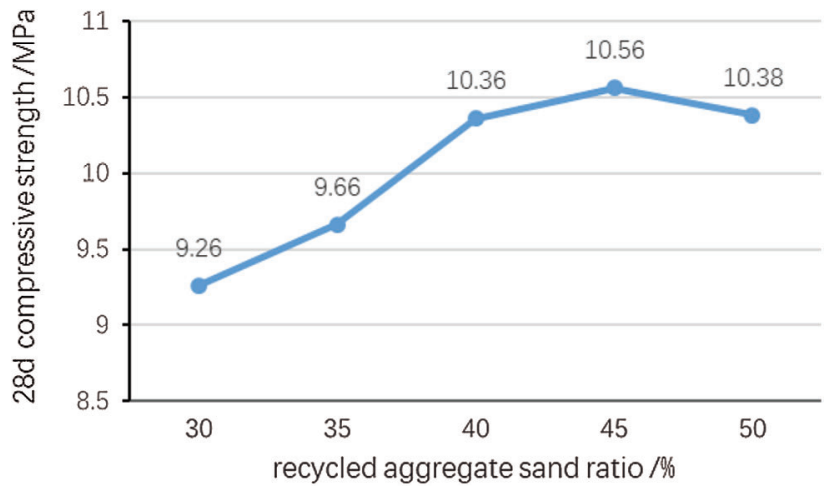

Figure 8: Influence of recycled aggregate sand ratio on $28 \mathrm{~d}$ compressive strength

The main reason for this phenomenon is: recycled coarse aggregates after crushing process will have a larger surface roughness and more corners. When the proportion of recycled coarse aggregates in recycled aggregates is relatively high, the cement mortar formed in concrete is not enough to cover the gap between aggregates surface and filled aggregates [37]. When the raw materials are mixed, the workability of the formed slurry will become worse, which makes the segregation and bleeding more likely, and the defects in the slurry will increase accordingly. After mixing evenly, a large number of pores will exist between coarse aggregates particles. In the process of material compression, these pores are easy to be damaged, making the compressive strength of the sample lower. On the contrary, when the proportion of fine aggregates in recycled aggregates increases, the cement mortar in concrete increases gradually [37], fine aggregates can play a role of lubrication in the slurry, thereby reducing the friction resistance between coarse aggregates particles and increasing the workability of the slurry. At the same time, fine aggregates will be filled into the gap between coarse aggregates, so that the number of pores between particles is reduced, thereby improving the structural compactness of insulation concrete blocks matrix material. 
Therefore, with the increase of the proportion of recycled fine aggregates, the compressive strength of the sample is also gradually increasing. When the proportion of fine aggregates reaches $45 \%$, the compressive strength reaches the maximum of $10.56 \mathrm{MPa}$.

With the increase of sand ratio, the compressive strength will decrease, because when the proportion of fine aggregates is relatively high (greater than $45 \%$ ), the total surface area of aggregates will increase. Therefore, the amount of cement slurry used to coat fine aggregates will increase. Without changing the amount of cement slurry, the amount of slurry coated on the surface of aggregates will decrease. The skeleton effect of coarse aggregates is weakened with the increase of sand content and the decrease of coarse aggregates content [38]. Compared with the recycled coarse aggregates, the water absorption of recycled fine aggregates is higher, which will reduce the actual water cement ratio of cement slurry, and the fluidity will deteriorate accordingly. These two factors reduce the workability of concrete mixture, so that the compressive strength of thermal insulation concrete block samples gradually reduced.

\subsubsection{Effect of Recycled Aggregates Active Activator on the Performance of Insulation Concrete Block}

In this study, two kinds of active activators were selected: $\mathrm{Ca}(\mathrm{OH})_{2}$ and $\mathrm{Na}_{2} \mathrm{SO}_{4}$. By changing the content of $\mathrm{Ca}(\mathrm{OH})_{2}$ and $\mathrm{Na}_{2} \mathrm{SO}_{4}$ in turn, with $0.05 \%, 0.10 \%, 0.15 \%, 0.20 \%$ and $0.25 \%$, respectively, the compressive strength of self-insulation concrete block samples is studied. The test results are shown in Fig. 9.

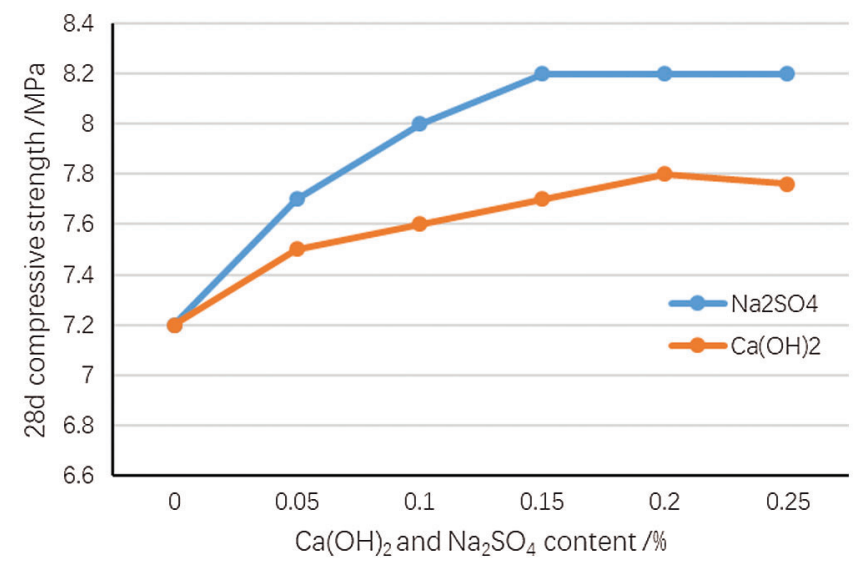

Figure 9: Effect of $\mathrm{Ca}(\mathrm{OH})_{2}$ and $\mathrm{Na}_{2} \mathrm{SO}_{4}$ content on compressive strength of block

It can be seen from the variation trend that: (1) The addition of $\mathrm{Ca}(\mathrm{OH})_{2}$ and $\mathrm{Na}_{2} \mathrm{SO}_{4}$ can improve the compressive strength of the insulation concrete block samples to different degrees. (2) Under the same content of $\mathrm{Ca}(\mathrm{OH})_{2}$ and $\mathrm{Na}_{2} \mathrm{SO}_{4}$, it can be clearly seen that the influence of $\mathrm{Na}_{2} \mathrm{SO}_{4}$ on the strength of the block is greater than that of $\mathrm{Ca}(\mathrm{OH})_{2}$, and the difference is obvious. (3) When the addition of $\mathrm{Ca}(\mathrm{OH})_{2}$ and $\mathrm{Na}_{2} \mathrm{SO}_{4}$ increased, the variation trend of compressive strength of the samples was basically the same, showing a trend of first increase and then stability. It can be determined that the optimum content of $\mathrm{Ca}(\mathrm{OH})_{2}$ is $0.20 \%$, the optimum content of $\mathrm{Na}_{2} \mathrm{SO}_{4}$ is $0.15 \%$, and the corresponding compressive strength is $7.8 \mathrm{MPa}$ and $8.2 \mathrm{MPa}$, respectively, which is $8.3 \%$ and $13.9 \%$ higher than that of the blank sample. (4) $\mathrm{Ca}(\mathrm{OH})_{2}$ and $\mathrm{Na}_{2} \mathrm{SO}_{4}$ can meet the requirements of MU5.0 strength grade under the condition of the best dosage, and have a certain excess strength.

The main components of recycled aggregates from C\&D waste are concrete recycled aggregates, mortar recycled aggregates and clay brick recycled aggregates. The concrete recycled aggregates and mortar recycled aggregates may contain unhydrated silicates, such as $\mathrm{C}_{2} \mathrm{~S}, \mathrm{C}_{3} \mathrm{~S}$, etc. Given certain conditions, 
hydration reaction can continue, which is conducive to the formation of hydrated calcium silicate gel. Therefore, these recycled aggregates have potential hydration activity. Similarly, the recycled aggregates of sintered clay brick contain $\mathrm{Al}-\mathrm{Si}$ vitreous body. $\mathrm{SiO}_{2}$ and $\mathrm{Al}_{2} \mathrm{O}_{3}$ in $\mathrm{Al}-\mathrm{Si}$ vitreous body are active, which can react with $\mathrm{Ca}(\mathrm{OH})_{2}$ to generate calcium silicate hydrate and calcium aluminate hydrate, so it also has potential hydration activity. If the activator is not added, the self-activity of recycled aggregates is difficult to be stimulated. Adding alkali activator and sulfate activator in the aggregates can fully and effectively stimulate its hydration activity, to improve the compressive strength of block samples. Observing the sample with an SEM, the interface of the sample without activator is relatively loose, as shown in Fig. 10a, and the interface of the sample with $0.15 \% \mathrm{Na}_{2} \mathrm{SO}_{4}$ is relatively close, as shown in Fig. 10b.

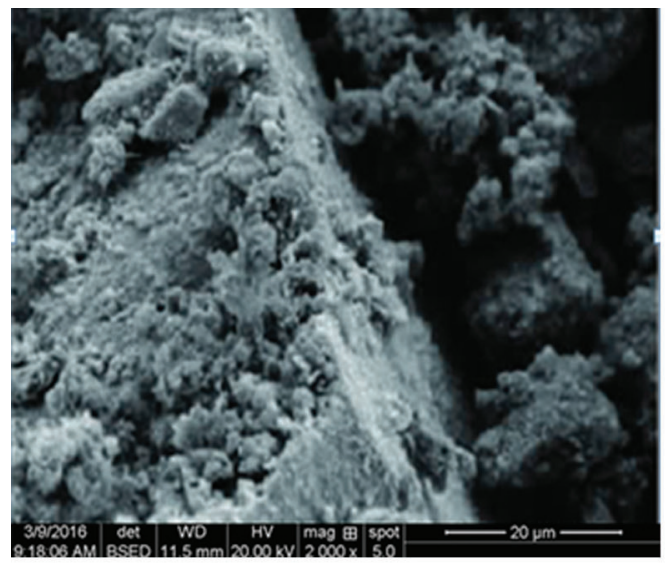

(a)

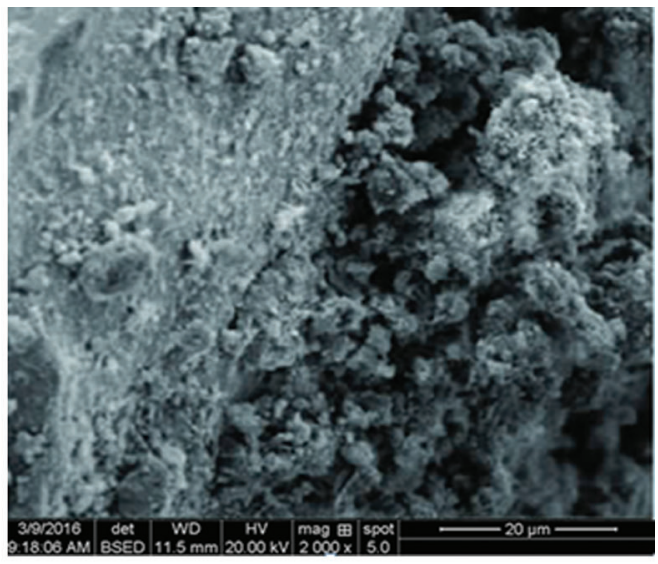

(b)

Figure 10: $\mathrm{SEM}$ of sample (a) sample without activator (b) sample with $0.15 \% \mathrm{Na}_{2} \mathrm{SO}_{4}$ content

\subsubsection{Effect of Fly Ash Content on the Performance of Insulation Concrete Block}

Fly ash contains soluble $\mathrm{SiO}_{2}$ and $\mathrm{Al}_{2} \mathrm{O}_{3}$, which have high potential hydration activity. In order to better improve the performance of the block, it is necessary to effectively stimulate the potential hydration activity of fly ash. In this experiment, the basic ratio was kept unchanged, and some cement was replaced by fly ash. The ratio of cement to material was 1: 5.0, and the consistency of mortar was $77 \mathrm{~mm}$. The proportion of fly ash is $0 \%, 5 \%, 10 \%, 15 \%, 20 \%, 25 \%, 30 \%$, and $35 \%$. The effect of fly ash content on the performance of blocks is shown in Fig. 10.

As can be seen from Fig. 11, the compressive strength of the block decreases with the increase of fly ash content. Although the strength decreases when the fly ash content is less than $20 \%$, the decrease is small. When the fly ash content is $30 \%$, the compressive strength of the block is $5.45 \mathrm{MPa}$. When the fly ash content is greater than $30 \%$, the compressive strength of the block is less than $5.0 \mathrm{MPa}$. In order to ensure the strength performance index of insulation concrete block, the optimum dosage of fly ash is determined to be $\leq 30 \%$.

\subsubsection{Thermal Insulation Performance of Concrete Block}

The thermal insulation performance of concrete blocks mainly depends on the performance of thermal insulation materials. The types of thermal insulation materials include organic and inorganic thermal insulation materials. Organic insulation materials have excellent thermal insulation performance, including foamed polystyrene board, extrusion board, polycarbonate, rigid foam polyurethane and phenolic foam plastics. In this experiment, polystyrene foam insulation board (also known as EPS insulation board) was used as the sandwich insulation material of insulation concrete block. 


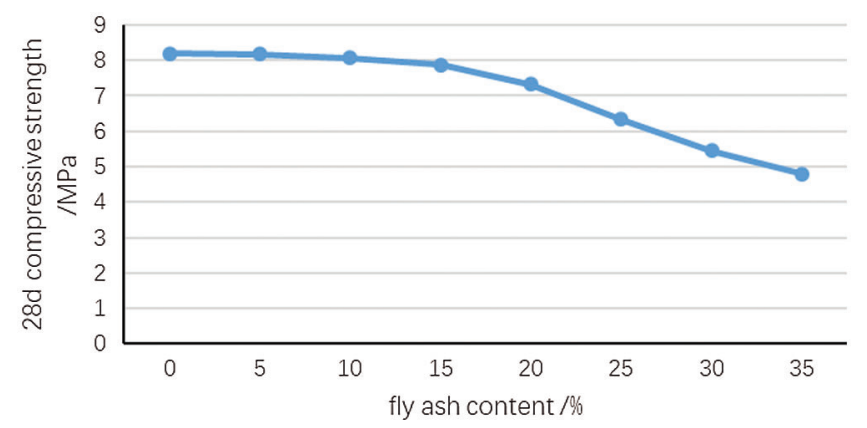

Figure 11: Influence of fly ash content on $28 \mathrm{~d}$ compressive strength of blocks

EPS insulation board is a foam material with closed cell structure formed by foaming and molding with polystyrene resin as the main component. It has the advantages of small thermal conductivity, good thermal insulation effect and lightweight. It is an ideal thermal insulation material and has wide market demand.

In this experiment, a polystyrene board with the density of $18-20 \mathrm{~kg} / \mathrm{m}^{3}$ was used as raw material to prepare the insulation concrete block, and its thermal conductivity was $0.0361-0.040 \mathrm{~W} /(\mathrm{m} \cdot \mathrm{K})$. According to the national standard of building energy-saving $75 \%$, the thermal resistance of the wall should not be less than $2.5 \mathrm{~m}^{2} \cdot \mathrm{K} / \mathrm{W}$. According to this thermal resistance value, the thickness of the EPS insulation board is as follows:

The thermal resistance of the 1-meter-thick EPS insulation board is $1 / 0.04=25\left(\mathrm{~m}^{2} \cdot \mathrm{K} / \mathrm{W}\right)$

The thermal resistance of the 0.1 -meter-thick EPS insulation board is $0.1 / 0.04=2.5\left(\mathrm{~m}^{2} \cdot \mathrm{K} / \mathrm{W}\right)$

In other words, if the thermal insulation performance of concrete is ignored, the thickness of the sandwich layer of the insulation concrete block should not be less than $0.1 \mathrm{~m}$, so we designed the block structure of the insulation concrete block as shown in Fig. 12. The thickness of the middle insulation layer is $60 \mathrm{~mm}$, and the thickness of the insulation layer on both sides is $50 \mathrm{~mm}$. According to the thermal design calculation method of GB 50176-2016 "Code for thermal engineering of civil buildings", the thermal resistance value of the sample is $3.28\left(\mathrm{~m}^{2} \cdot \mathrm{K} / \mathrm{W}\right)$. According to GB/T 13475-2008 "The determination of thermal insulation steady state heat transfer properties-Calibration and protection hot box method", the thermal resistance of insulation concrete block masonry wall is tested by hot box method, and the actual thermal resistance value is $2.62\left(\mathrm{~m}^{2} \cdot \mathrm{K} / \mathrm{W}\right)$, which meets the national standard of $75 \%$ energy saving.

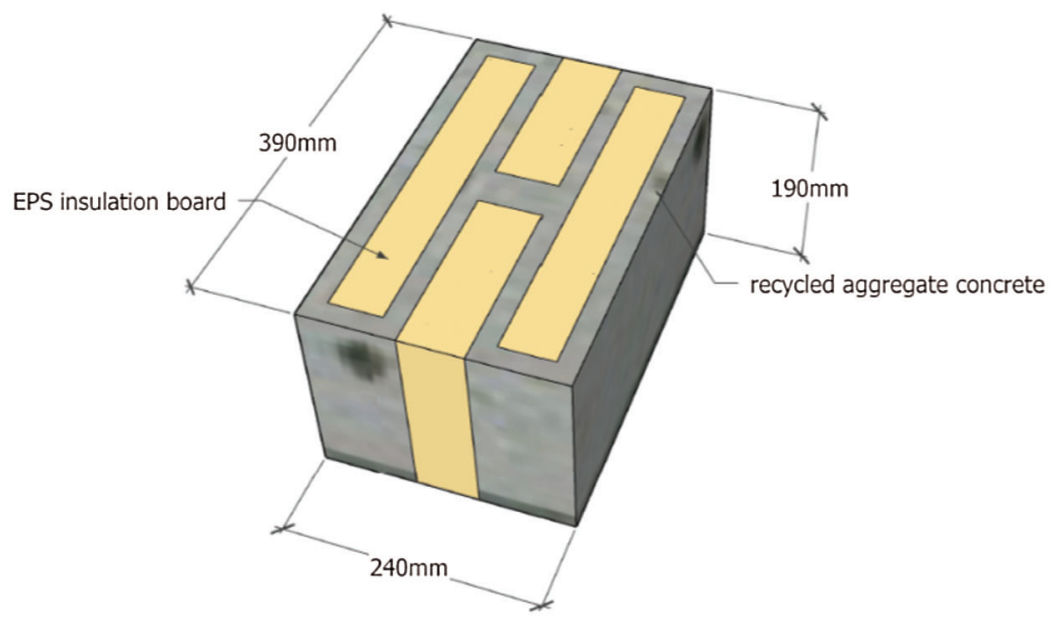

Figure 12: Thermal insulation concrete block 
The thermal design calculation method:

$\bar{R}=\frac{R_{o u}+R_{o l}}{2}-\left(R_{i}+R_{e}\right)$

$R_{\text {ou }}=\frac{1}{\sum_{i=1}^{n} \frac{f_{i}}{R_{\text {oui }}}}$

$R_{o l}=R_{i}+\sum_{j=1}^{n} R_{j}+R_{e}$

$R_{j}=\frac{1}{\sum_{i=1}^{n} \frac{f_{i}}{R_{i j}}}$

where $\bar{R}$ is the thermal resistance of heterogeneous composite enclosure structure $\left(\mathrm{m}^{2} \cdot \mathrm{K} / \mathrm{W}\right), R_{o u}$ is thermal resistance at isothermal heat transfer surfaces on both sides, $R_{o l}$ is thermal resistance when the inner heat transfer surface is isothermal, $R_{i}$ is internal surface heat resistance, $R_{i}=0.11\left(\mathrm{~m}^{2} \cdot \mathrm{K} / \mathrm{W}\right), R_{e}$ is external surface thermal resistance, $R_{i}=0.04\left(\mathrm{~m}^{2} \cdot \mathrm{K} / \mathrm{W}\right), f_{i}$ is the percentage of area to total area parallel to heat flow, $R_{\text {oui }}$ is the thermal resistance of parts parallel to heat flow, $R_{i j}$ is the thermal resistance of each part of layer $\mathrm{j}$ perpendicular to heat flow.

\section{Conclusions}

The experimental results show that the sand ratio of recycled aggregates, active activator and fly ash content have effects on the strength of insulation concrete blocks.

(1) With the increase of recycled aggregates sand ratio, the $28 \mathrm{~d}$ compressive strength of the insulation block samples increases first and then decreases. When the sand ratio is $45 \%$, the compressive strength of the sample reaches the maximum. When the sand ratio is $40 \%$ and $50 \%$, the compressive strength of the sample is basically the same.

(2) Both $\mathrm{Ca}(\mathrm{OH})_{2}$ and $\mathrm{Na}_{2} \mathrm{SO}_{4}$ can improve the compressive strength of recycled insulation concrete block samples, and the influence of $\mathrm{Na}_{2} \mathrm{SO}_{4}$ on the sample is more obvious than that of $\mathrm{Ca}(\mathrm{OH})_{2}$. When the content of $\mathrm{Ca}(\mathrm{OH})_{2}$ is $0.2 \%$ and $\mathrm{Na}_{2} \mathrm{SO}_{4}$ is $0.15 \%$, the test performance of the sample is the best.

(3) With the increase of fly ash content, the compressive strength of insulation block samples decreases gradually. When the fly ash content is less than $15 \%$, the compressive strength of the sample decreases slightly. When the fly ash content is more than $20 \%$, the compressive strength of the sample decreases rapidly.

(4) The insulation block adopts the three-layer EPS insulation board structure. When the thickness of the middle layer is $60-80 \mathrm{~mm}$ and the two sides' layer is $50-70 \mathrm{~mm}$, the equivalent thermal resistance calculation and the actual detection of the thermal resistance value meet the current building energysaving $75 \%$ standard requirements.

Funding Statement: This work was supported by Science and technology project of housing and urban-rural Development Department of Shandong Province (2018) and Shandong Provincial Social Science Planning Research Project (20CGLJ13).

Conflicts of Interest: The authors declare that they have no conflicts of interest to report regarding the present study. 


\section{References}

1. Wang, Y. L. (2019). The pilot project of construction and demolition waste treatment in China is progressing smoothly. http://www.gov.cn/xinwen/2019-07/14/content 5409176.htm.

2. China Association of Building Energy Efficiency (2021). China Building Energy Consumption Annual Report 2020. Journal of BEE, 49, 1-6.

3. Ge, X. Y. (2014). Research on application of salvaged materials and regenerative materials in the context of resource-efficient landscape (Master Thesis). Beijing Forestry University, Beijing.

4. Xie, H. Y. (2020). The current situation and direction of circular economy under the green development. Hongguan Jingji Guanli, 1, 14-21. DOI 10.19709/j.cnki.11-3199/f.2020.01.005.

5. Banias, G., Achillas, C., Vlachokostas, C., Moussiopoulos, N., Tarsenis, S. (2010). Assessing multiple criteria for the optimal location of a construction and demolition waste management facility. Building and Environment, 45, 2317-2326. DOI 10.1016/j.buildenv.2010.04.016.

6. Mihai, F. C. (2019). Construction and demolition waste in Romania: The route from illegal dumping to building materials. Sustainability, 11, 3179. DOI 10.3390/su11113179.

7. Fischer, C., Werge, M. (2009). EU as a recycling society, present recycling levels of municipal waste and construction \& demolition waste in the EU. European Topic Centre on Resource and Waste Management. http://webdog.brbs.nl/files/EU-as-recyclingsociety-CDW.pdf.

8. Kanellopoulos, A., Nicolaides, D., Petrou, M. F. (2014). Mechanical and durability properties of concretes containing recycled lime powder and recycled aggregates. Constrution and Building Material, 53, 253-259. DOI 10.1016/j.conbuildmat.2013.11.102.

9. Huang, B., Wang, X., Kua, H., Geng, Y., Bleischwitz, R. et al. (2018). Construction and demolition waste management in China through the 3R principle. Resources, Conservation and Recycling, 129, 36-44. DOI 10.1016/j.resconrec.2017.09.029.

10. Lu, M., Xiong, Z. H., Lin, X., Fang, K. J., Li, T. et al. (2019). Early strength performance of construction waste regenerarion brick. Environmental Engineering, 37, 173-176. DOI 10.13205/j.hjgc.201908032.

11. Qiao, L., Liu, D. D., Yuan, X. L., Wang, Q. S., Ma, Q. (2020). Generation and prediction of construction and demolition waste using exponential smoothing method: A case study of Shandong Province, China. Sustainability, 12, 5094. DOI 10.3390/su12125094.

12. Technical Code for Construction and Demolition Waste Treatment. CJJ134-(2017).

13. Silva, R. V., Brito, J., Dhir, R. K. (2014). Properties and composition of recycled aggregates from construction and demolition waste suitable for concrete production. Construction and Building Materials, 65, 201-217. DOI 10.1016/j.conbuildmat.2014.04.117.

14. Abu El-Maaty Behiry, A. E. (2013). Utilization of cement treated recycled concrete aggregates as base or subbase layer in Egypt. Ain Shams Engineering Journal, 4, 661-673. DOI 10.1016/j.asej.2013.02.005.

15. Xiao, J. Z., Li, W. G., Fan, Y. H., Huang, X. (2012). An overview of study on recycled aggregates concrete in China (1996-2011). Construction and Building Materials, 31, 364-383. DOI 10.1016/j.conbuildmat.2011.12.074.

16. Menga, Y. Z., Linga, T. C., Mob, K. H. (2018). Recycling of wastes for value-added applications in concrete blocks: An overview. Resources, Conservation and Recycling, 138, 298-312. DOI 10.1016/j. resconrec.2018.07.029.

17. Reporter (2019). "Aggregates 4.0 +": New development direction of aggregates industry in China. China Building Materials, 7, 56-59. DOI 10.16291/j.cnki.zgjc.2019.07.009.

18. Cardoso, R., Silva, R. V., Brito, J. D., Dhir, R. (2016). Use of recycled aggregates from construction and demolition waste in geotechnical applications: A literature review. Waste Management, 49, 131-145. DOI 10.1016/j.wasman.2015.12.021.

19. Jin, R., Li, B., Zhou, T., Wanatowski, D., Piroozfar, P. (2017). An empirical study of perceptions towards construction and demolition waste recycling and reuse in China. Resources, Conservation and Recycling, 126, 86-98. DOI 10.1016/j.resconrec.2017.07.034. 
20. Soutsos, M. N., Tang, K., Millard, S. G. (2011a). Concrete building blocks made with recycled demolition aggregates. Construction and Building Materials, 25, 726-735. DOI 10.1016/j.conbuildmat.2010.07.014.

21. Soutsos, M. N., Tang, K., Millard, S. G. (2011b). Use of recycled demolition aggregates in precast products, phase II: Concrete paving blocks. Construction and Building Materials, 25, 3131-3143. DOI 10.1016/j. conbuildmat.2010.12.024.

22. Bravo, M., Brito, J. D., Pontes, J., Evangelista, L. (2015). Mechanical performance of concrete made with aggregates from construction and demolition waste recycling plants. Journal of Cleaner Production, 99, 59-74. DOI 10.1016/j.jclepro.2015.03.012.

23. Zhang, J. H., Ding, L., Li, F. (2020). Recycled aggregates from construction and demolition wastes as alternative filling materials for highway subgrades in China. Technology News Focus, 255, 120223. DOI 10.1016/j. jclepro.2020.120223.

24. Zhang, S. P., He, P. L., Niu, L. L. (2020). Mechanical properties and permeability of fiber-reinforced concrete with recycled aggregates made from waste clay brick. Journal of Cleaner Production, 268, 121690. DOI 10.1016/j. jclepro.2020.121690.

25. Yu, Q. B., Sun, J. Q., Zeng, X., Qin, K. Y. (2020). Experimental research on compression performance of coal gangue sintered composite insulation block masonry. Industrial Construction, 50(5), 75-80. DOI 10.13204 /j. gyjz202005013.

26. Fang, G. X., Wang, Z. (2019). Mechanical properties and durability test on a new type of composite self-insulating block. Architecture Technology, 50(12), 1527-1530. DOI CNKI:SUN:JZJI.0.2019-12-043.

27. Zhang, X. (2019). Study on volcanic slag concrete composite self-insulation block (Master Thesis). Yangzhou University, China.

28. Ge, Z. Z., Yan, Z. F. (2019). Study on application technology of HB concrete self-insulated block. Urbanism and Architecture, 12(2), 107-109. DOI 10.19892/j.cnki.csjz.2019.05.042.

29. Li, Z. L., Zhang, Z. Y., Song, H. X., Zang, Y. J., Bu, W. K. et al. (2020). Experimental study on composite thermal insulation block of construction waste ceramsite concrete. Housing and Real Estate, 2, 109-110. DOI CNKI:SUN: ZZFD.0.2020-06-098.

30. Xu, N. Z., Ma, G. X., Sun, Y. G., Ba, T. E. (2020). Performance analysis and experimental study of a new type of self-insulation block for full-break bridge. Green Building Materials, 4, 23-24. DOI 10.16767/j.cnki.10-1213/ tu.2020.04.016.

31. Zhang, H. Z., Zheng, J. L. (2016). Heat transfer characteristics of recycled concrete self-insulation block wall. Journal of Building Materials, 19(2), 304-309. DOI 10.3969/j.issn.1007-9629.2016.02.016.

32. He, X. X., Liang, X. M. (2014). Development of load-bearing thermal insulation recycled concrete block and research on its thermal performance. Advanced Materials Research, 1004-1005, 1503-1507. DOI 10.4028/ www.scientific.net/AMR.1004-1005.1503.

33. Liu, W. K., Chen, Y. S., Xu, M. (2014). Experimental research on the compression performance ofrecycled concrete self-insulation load-bearing block masonry. Industrial Construction, 44(1), 84-89. DOI 10.13204/j.gyjz201401019.

34. Zhao, Z. F., Courard, L., Groslambert, S., Jehin, T., Xiao, J. (2020). Use of recycled concrete aggregates from precast block for the production of new building blocks: An industrial scale study. Resources Conservation and Recycling, 157, 104786. DOI 10.1016/j.resconrec.2020.104786.

35. Akkadath, A., Weerachart, T., Chai, J. (2019). Environmentally friendly interlocking concrete paving block containing new cementing material and recycled concrete aggregates. European Journal of Environmental and Civil Engineering, 23, 1467-1484. DOI 10.1080/19648189.2017.1355265.

36. Huang, Y. S., Meng, Y., He, J. Y., Li, J. L., Xu, R. C. et al. (2019). Influence of EPS filling methods and filling rates on thermal insulation performance of composite self-insulating blocks. 2nd International Conference of Green Buildings and Environmental Management, 310 (4), 042060. DOI 10.1088/1755-1315/310/4/042060.

37. Zhou, M. L., Ke, G. J. (2016). Influence of sand ratio on the workability and compressive strength of concrete with coal gangue powder. Concrete, 8, 133-135. DOI 10.3969/j.issn.1002-3550.2016.08.035.

38. Wang, C. Q. (2018). Experimental study on mechanical properties and pervious performance of recycled mixed aggregates pervious concrete (Master Thesis). China University of Mining and Technology. 